Article

\title{
Developing (Quantitative Structure Property Relationships) QSPR Techniques to Predict the Char Formation of Polybenzoxazines
}

\author{
Maryam Sairi ${ }^{1}$, Brendan Howlin ${ }^{1, *}$ and Ian Hamerton ${ }^{2}$ \\ 1 Department of Chemistry, Faculty of Engineering and Physical Sciences, University of Surrey, Guildford, \\ Surrey, GU2 7XH, UK; m.sairi@surrey.ac.uk \\ 2 The Advanced Composites Centre for Innovation and Science, Department of Aerospace Engineering, \\ University of Bristol, Queen's Building, University Walk, Bristol, BS8 1TR, UK; i.hamerton@bristol.ac.uk \\ * Correspondence: b.howlin@surrey.ac.uk; Tel.: +44-1483-686248
}

Academic Editor: Xianqiao (XQ) Wang

Received: 6 November 2015; Accepted: 18 April 2016; Published: 25 April 2016

\begin{abstract}
This study uses the Molecular Operating Environment software (MOE) to generate models to calculate the char yield of polybenzoxazines (PBz). A series of benzoxazine (Bz) monomers were constructed to which a variety of parameters relating to the structure (e.g., water accessible surface, negative van der Waals surface area and hydrophobic volume, etc.) were obtained and a quantitative structure property relationships (QSPR) model was generated. The model was used to generate data for new Bz monomers with desired properties and a comparison was made of predictions based on the QSPR model with the experimental data. This study shows the quality of predictive models and confirms how useful computational screening is prior to synthesis.
\end{abstract}

Keywords: polybenzoxazines; thermal stability; char formation; mathematical modelling; QSPR

\section{Introduction}

Thermoset polymers have an established history in civil aviation, in applications involving decorative panels, secondary composite structures and adhesives typically around $90 \%$ of the interior furnishings of a typical civil airliner will contain thermoset composites [1]. The development of structural materials with improved thermal stability and fire resistance is key in this area to retard the spread of fire, and modern legislation is leading to the removal of halogenated flame retardants [2]. This is often achieved by introducing highly aromatic or hetero-aromatic materials such as polybenzoxazines (PBZs) [3] (Scheme 1) that form intumescent chars during the combustion process, with the polymer swelling and becoming porous to protect the underlying structure [4]. PBZs are a comparatively recent addition to the commercial thermosetting resins, but there is great interest in their potential as replacements for phenolics [5] or epoxy resins [6] and, whilst they are not currently widely used in civil aviation, they are being evaluated in this application. 


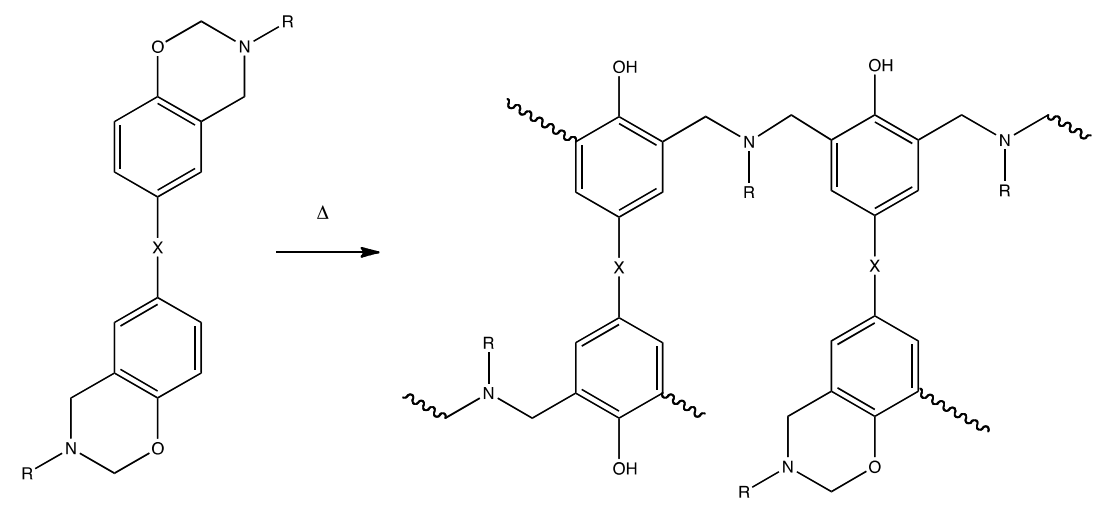

Scheme 1. Schematic showing polymerisation of bisbenzoxazines through ring opening and crosslinking.

Cured PBZs offer a combination of favourable thermal and mechanical performance (e.g., dry $T_{\mathrm{g}}$ values of $255^{\circ} \mathrm{C}$, wet $T_{\mathrm{g}}=196^{\circ} \mathrm{C}$ are possible [7], coupled with very low moisture uptake) that gives an attractive property profile. PBZs have the potential to compete with conventional phenolics in terms of high thermal stability and flame resistance. In previous work [8] we have examined the thermal stability of cured PBZs and investigated the influence of particle size and the structure of the bisphenyl unit on the manner in which the crosslinked polymer undergoes degradation. Molecular modelling of polymers is a growing area and was reviewed in a special edition of the Journal of Polymer Science in 2015 where Ginzberg, Weinhold and Trefonas stated that "In the near future, modeling is expected to be an integral part of formulation design and the screening process" [9]. It was reported that the modelling work was proven to be useful to predict properties such as the temperature, decomposition, softening and failure of composites on a bulk scale, reflecting the size of some actual components [10]. The work shows the ability of the model to give a good agreement between the prediction data and the experimental data on most of the properties that were examined. While the work was focusing on composites on a bulk scale, we, on the other hand, are trying to utilize modelling on to the molecular and atomistic scale. The whole area of molecular scale modelling of thermosets was reviewed by Li and Strachan where we were credited with publishing the first fully atomistic molecular dynamics simulation of a thermoset [11]. Another way to use atomistic modelling of thermosets is in Quantitative Structure Property Relationships (QSPR) which is the polymer analogue of Quantitative Structure Activity Relationships (QSAR) widely used in drug design to develop new pharmaceuticals. With QSPR we seek to relate the structure of the monomer of particular polymer to the physical, mechanical and thermal properties of the derived polymer using mathematical methods. This technique has been pioneered by Hopfinger [12], Katrizky [13] and Bicerano [14] in particular and is the source of several commercial software packages. We are particularly interested in the potential to predict structure-property relationships and have had some success in using quantitative structure property relationships (QSPR) towards the prediction of e.g., the glass transition temperature or degree of cure achieved [15]. In the current study, we concentrate on the refinement of this method and achieve a level of accuracy that is comparable with the experimental determination of char yield by thermogravimetric analysis (TGA).

\section{Methodology}

Molecular Operating Environment (MOE) software by Chemical Computing Group (Cambridge, UK) was used to run QSPR and generate models to calculate the predicted char yield of thirty-two benzoxazines (the training set). The Partial Least Squares (PLS) regression algorithm was used to analyse the relationship between the actual char yield (measured by experimental work) and the predicted char yield (calculated using the model). PLS was chosen because it contains the fewest number of factors therefore it provides maximum correlation with the dependant variables. 
There are six main steps to generate a model with the best final linear model equation:

1. The training data set was chosen from the Handbook of Benzoxazine Resins. This training set is a secondary data set and consists of thirty-two benzoxazines with corresponding actual char yield measured by different research groups.

2. All monomers were built using the builder menu in MOE and a conformational search using Low Mode Molecular Dynamics [16] was carried out on each monomer before energy minimising the lowest energy conformer of each model to convergence.

3. A series of descriptors [17] were calculated for each monomer, which cover molecular volume, shape, charge, etc.

4. A QSPR equation as developed to relate the descriptors to the experimentally determined char yield using partial least squares (PLS) [18].

5. Descriptors which play a major role in influencing the model were chosen. The linear model equation with the highest coefficient of determination $\left(r^{2}\right)$ was selected and further analysis was done on this model.

6. The descriptors were then used to calculate the prediction values and the average percentage error of the data produced was calculated in-silico.

7. The Leave-One-Out-Cross-Validation test [19] was carried out by the model to evaluate whether it could be taken further and capable to produce accurate prediction values. This test was done by taking out one of the materials in the training set and applying the model to that chosen material.

8. The experimental data of the material used in the validation test was compared against the predicted/calculated data. The percentage error and difference error between the two values was calculated and a conclusion was made based on the comparison values.

\section{Results and Discussion}

The training data set that was used in this research was compiled from various papers in the Handbook of Benzoxazine Resins [3]. The data set consists of thirty-two benzoxazine monomers and their recorded percentage char yields as polybenzoxazines reported by various sources. Char yields are normally taken from Thermogravimetric Analysis (TGA) under a nitrogen atmosphere, as these materials tend to burn away completely in oxygen atmospheres in the TGA. The list of the monomers in the data set is shown in Table 1.

Table 1. List of \% char yield of thirty-three benzoxazine monomers (the training set). The definition of the abbreviation used for each benzoxazine are given in the Abbreviations at the end of the paper.

\begin{tabular}{cccccc}
\hline No. & Materials & Char yield (\%) & No. & Materials & Char yield (\%) \\
\hline 1 & HQ-apa & $81[20]$ & 17 & TP-a & $57[21]$ \\
2 & BZ-apa & $80[20]$ & 18 & MIB-a & $56[22]$ \\
3 & PH-apa & $79[3],(81)[20]$ & 19 & BPPPO-a & $51[23]$ \\
4 & TP-apa & $79[20]$ & 20 & BHPPO-m & $48[23]$ \\
5 & BF-apa & $78[20]$ & 21 & TrisP-a & $47[21]$ \\
6 & BS-apa & $78[20]$ & 22 & BHPPO-a & $46[3],(41)[23]$ \\
7 & NP-apa & $76[20]$ & 23 & HQ-a & $44[21]$ \\
8 & BPPPO-ea & $76[23]$ & 24 & P-ad2 & $41[24]$ \\
9 & BO-apa & $75[20]$ & 25 & P-ad4 & $32[24]$ \\
10 & BA-apa & $74[20]$ & 26 & BA-a & $32[20,25]$ \\
11 & BP-apa & $73[20]$ & 27 & BPPPO-m & $30[23]$ \\
12 & BAF-apa & $71[20]$ & 28 & PC-a & $20[21]$ \\
13 & 15N-a & $71[21]$ & 29 & P-ad6 & $19[24]$ \\
14 & 4,4 O-a & $65[26]$ & 30 & P-ad8 & $1[24]$ \\
15 & BHPPO-ea & $64[23]$ & 31 & P-ad12 & $6[24]$ \\
16 & BAF-a & $57[3]$ & 32 & NOB-a & $58[22]$ \\
\hline
\end{tabular}


The training set consists of a mixture various structures of benzoxazines including acetylene-based benzoxazines, aniline-based benzoxazines, aliphatic benzoxazines, benzoxazines containing phenylphosphine oxide, monofunctional benzoxazines and benzoxazines with fused-ring bridges (Figure 1). The full structures of each material are given in the Supplementary Material.

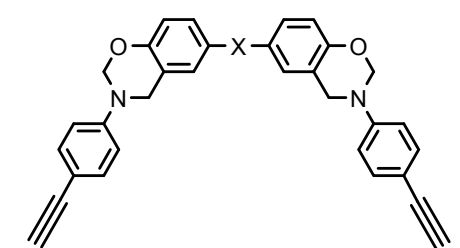

Acetylene-based benzoxazines

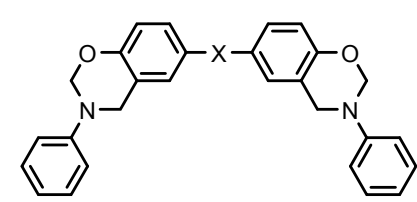

Aniline-based benzoxazines
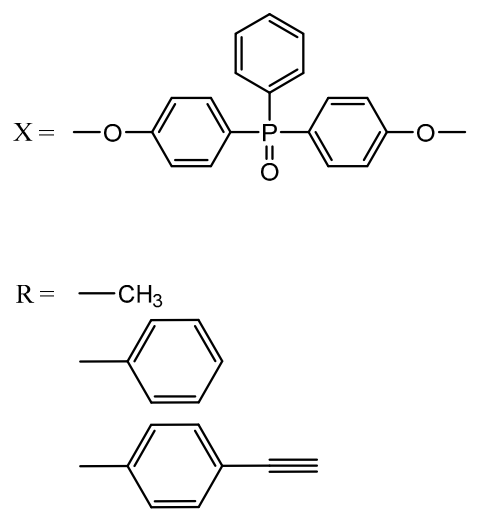

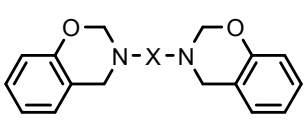

Aliphatic benzoxazines<smiles>[R]N1COc2ccc([X]c3ccc4c(c3)CN([R])CO4)cc2C1</smiles><smiles>CP(=O)(O)c1ccccc1</smiles>

Benzoxazines containing phenylphosphine oxide

Figure 1. The general structure of some of benzoxazines in the training set.

Since the data set is secondary data from a variety of sources, it is expected to contain significant errors as it was reported by different teams from various places, using potentially different methods. This fact was supported by a set of compiled data from the literature that shows the errors from secondary data measurements can be up to $14 \%$ (Table 2). For instance, the data set (Table 2) consists of five measurements of the percentage char yield on the polybenzoxazine formed from bisphenol A and aniline (BA-a) reported by different research groups and collected from different articles from the literature.

Based on Table 2, the error associated with the data set is $14 \%$, which exceeds the acceptable $10 \%$ experimental error by $4 \%$. However, it is believed that the significantly high error in the measurements is due to the different parameters that were used in the measurements (e.g., different temperature and different heating rate). There are also other potential parameters that might contribute to the large errors in the measurements such as different sample size used, the different thickness and shape of the crucibles and the physical condition of the sample, either in bulk or in powder [27].

Table 2. Experimental error of six BA-a char yield measurements conducted at different temperatures and heating rates.

\begin{tabular}{|c|c|c|c|c|c|c|c|}
\hline $\begin{array}{c}\text { Temperature } \\
\left({ }^{\circ} \mathrm{C}\right)\end{array}$ & $\begin{array}{l}\text { Heating rate } \\
(\mathrm{K} / \mathrm{min})\end{array}$ & $\begin{array}{c}\text { Measured } \\
\text { char yield } \\
(\%), Y_{c}\end{array}$ & Mean, $\bar{Y}_{\mathbf{c}}$ & $\begin{array}{c}\text { Difference } \\
\text { error, } \mathbf{Y}_{c}-\bar{Y}_{c}\end{array}$ & $\begin{array}{c}\text { Average } \\
\text { difference } \\
\text { error }\end{array}$ & $\begin{array}{c}\text { Percentage } \\
\text { error }(\%)\end{array}$ & $\begin{array}{c}\text { Average } \\
\text { percentage } \\
\text { error (\%) }\end{array}$ \\
\hline \multirow{4}{*}{800} & 20 & $24.30[28]$ & \multirow{5}{*}{28.72} & 4.42 & \multirow{5}{*}{4.06} & 18.19 & \multirow{5}{*}{14.00} \\
\hline & 20 & 32.00 [20] & & 3.28 & & 10.25 & \\
\hline & 10 & 35.60 [29] & & 6.88 & & 19.33 & \\
\hline & 10 & $25.70[30]$ & & 3.02 & & 11.75 & \\
\hline 900 & 20 & $26.00[31]$ & & 2.72 & & 10.46 & \\
\hline
\end{tabular}


As the degrees of freedom were reduced, it was found that the error in the measurements was also reduced. This statement is supported by the data set in Table 3, which combines experimental data for the percentage char yield of the same material, BA-a measured at $800^{\circ} \mathrm{C}$ with an experimental heating rate of $10 \mathrm{~K} / \mathrm{min}$. It shows that by keeping these two parameters constant, the experimental error was greatly reduced from $14 \%$ to only $10.48 \%$.

Table 3. Experimental error of six BA-a char yield measurements reported at the same temperature $\left(800{ }^{\circ} \mathrm{C}\right)$ and heating rate $(10 \mathrm{~K} / \mathrm{min})$.

\begin{tabular}{ccccccc}
\hline $\begin{array}{c}\text { Temperature } \\
\left({ }^{\circ} \mathbf{C}\right)\end{array}$ & $\begin{array}{c}\text { Measured } \\
\text { char yield } \\
\mathbf{( \% )}, \mathbf{Y}_{\mathbf{c}}\end{array}$ & Mean, $\bar{Y}_{\mathbf{c}}$ & $\begin{array}{c}\text { Difference } \\
\text { error, } \mathbf{Y}_{\mathbf{c}}-\bar{Y}_{\mathbf{c}}\end{array}$ & $\begin{array}{c}\text { Average } \\
\text { difference } \\
\text { error }\end{array}$ & $\begin{array}{c}\text { Percentage } \\
\text { error (\%) }\end{array}$ & $\begin{array}{c}\text { Average } \\
\text { percentage } \\
\text { error (\%) }\end{array}$ \\
\hline \multirow{3}{*}{800} & $26.62[32]$ & & 1.16 & & 4.36 & \\
& $25.00[33]$ & & 2.78 & & 11.12 & 10.48 \\
& $26.00[34]$ & 27.78 & 1.78 & 3.12 & 6.85 & 21.97 \\
\hline
\end{tabular}

Tables 2 and 3 contain examples of secondary data. To compare the quality of secondary data to primary data, a series of measurements are made on the same material and reported by a "single" group (within this department) (Table 4). All parameters were kept constant as much as possible; the same temperature $\left(800^{\circ} \mathrm{C}\right)$, heating rate $(10 \mathrm{~K} / \mathrm{min})$ and method, including the experimental apparatus. It was found that the measurement readings are very consistent with a very small experimental error which is only $2.26 \%$ compared to $10.48 \%$ from the previous data set (Table 3 ).

Table 4. Experimental error of three BA-a char yield measurements done by a "single" group study.

\begin{tabular}{ccccccc}
\hline $\begin{array}{c}\text { Temperature } \\
\left({ }^{\circ} \mathbf{C}\right)\end{array}$ & $\begin{array}{c}\text { Measured } \\
\text { char yield } \\
\mathbf{( \% )}, \mathbf{Y}_{\mathbf{c}}\end{array}$ & Mean, $\bar{Y}_{\mathbf{c}}$ & $\begin{array}{c}\text { Difference } \\
\text { error, } \mathbf{Y}_{\mathbf{c}}-\bar{Y}_{\mathbf{c}}\end{array}$ & $\begin{array}{c}\text { Average } \\
\text { difference } \\
\text { error }\end{array}$ & $\begin{array}{c}\text { Percentage } \\
\text { error (\%) }\end{array}$ & $\begin{array}{c}\text { Average } \\
\text { percentage } \\
\text { error (\%) }\end{array}$ \\
\hline & $26.62[32]$ & & 0.75 & & 2.80 & \\
800 & $25.00[33]$ & 25.87 & 0.87 & 0.58 & 3.49 & 2.26 \\
\hline
\end{tabular}

Since secondary data was used as the training set for the current project, it is therefore to be expected that the percentage error in this work will be of the order of $10 \%$ to $14 \%$. The best equation derived for the char yield is shown in Table 5.

Table 5. The linear model equation produced from the model and the relative importance of each descriptor.

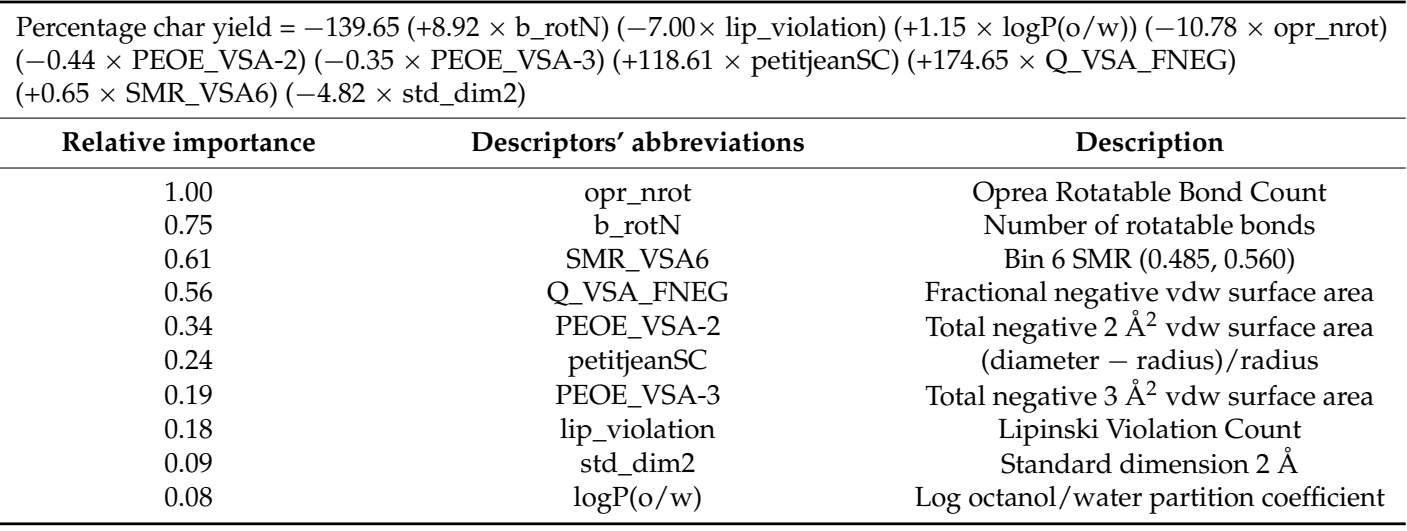


The two descriptors with the two highest relative importance ratings are the Oprea Rotatable Bond Count (opr_nrot) with $100 \%$ importance and the Number of rotatable bonds (b_rotN) with $75 \%$ importance (69\% importance from the previous model). The least important descriptor is the $\log \mathrm{P}(\mathrm{o} / \mathrm{w})$ with 0.03 importance. Hence the most important feature of a benzoxazine to increase char yield is the number of rotatable bonds in the monomer.

The prediction data in Table 6 were produced in-silico using descriptors from the table above. The errors between the prediction data and the actual data were then calculated manually using Microsoft Excel.

Table 6. Prediction data, calculated average error and average percentage error for lowest energy conformation quantitative structure property relationships (QSPR) model.

\begin{tabular}{|c|c|c|c|c|c|c|c|}
\hline Materials & Actual data (\%) & $\begin{array}{c}\text { Predicted } \\
\text { data (\%) }\end{array}$ & Difference error & Average error & $\%$ error & $\begin{array}{l}\text { Average } \\
\% \text { error }\end{array}$ & $R^{2}$ \\
\hline HQ-apa & 81.00 & 74.66 & 6.34 & & 7.82 & & \\
\hline BZ-apa & 80.00 & 82.75 & 2.75 & & 3.44 & & \\
\hline PH-apa & 79.00 & 84.69 & 5.69 & & 7.20 & & \\
\hline TP-ара & 79.00 & 75.25 & 3.75 & & 4.75 & & \\
\hline BF-apa & 78.00 & 77.82 & 0.18 & & 0.23 & & \\
\hline BS-apa & 76.00 & 76.55 & 0.55 & & 0.72 & & \\
\hline NP-apa & 78.00 & 82.14 & 4.14 & & 5.31 & & \\
\hline ВРРРО-еа & 76.00 & 72.19 & 3.81 & & 5.02 & & \\
\hline BO-ара & 75.00 & 78.04 & 3.04 & & 4.05 & & \\
\hline BA-apa & 74.00 & 64.07 & 9.93 & & 13.42 & & \\
\hline ВР-ара & 73.00 & 69.12 & 3.88 & & 5.31 & & \\
\hline BAF-apa & 71.00 & 75.61 & 4.61 & & 6.49 & & \\
\hline $15 \mathrm{~N}-\mathrm{a}$ & 71.00 & 65.94 & 5.06 & & 7.12 & & \\
\hline $4,4^{\prime} \mathrm{O}-\mathrm{a}$ & 65.00 & 57.64 & 7.36 & & 11.32 & & \\
\hline BHPPO-еa & 64.00 & 73.97 & 9.97 & & 15.57 & & \\
\hline NOB-a & 58.00 & 43.99 & 14.01 & 502 & 24.15 & 12.54 & $91.94 \%$ \\
\hline BAF-a & 57.00 & 52.39 & 4.61 & 5.02 & 8.08 & 12.04 & $91.94 \%$ \\
\hline $\mathrm{TP}-\mathrm{a}$ & 57.00 & 55.74 & 1.26 & & 2.22 & & \\
\hline MIB-a & 56.00 & 51.58 & 4.42 & & 7.89 & & \\
\hline ВРPPO-а & 51.00 & 52.74 & 1.74 & & 3.41 & & \\
\hline BHPPO-m & 48.00 & 41.58 & 6.42 & & 13.37 & & \\
\hline TrisP-a & 47.00 & 40.97 & 6.03 & & 12.82 & & \\
\hline ВНРPO-а & 46.00 & 52.51 & 6.51 & & 14.16 & & \\
\hline HQ-a & 44.00 & 45.46 & 1.46 & & 3.32 & & \\
\hline P-ad2 & 41.00 & 45.44 & 4.44 & & 10.83 & & \\
\hline BA-a & 32.00 & 45.22 & 13.22 & & 41.31 & & \\
\hline P-ad4 & 32.00 & 32.35 & 0.35 & & 1.09 & & \\
\hline BPPPO-m & 30.00 & 34.51 & 4.51 & & 15.05 & & \\
\hline PC-a & 20.00 & 30.69 & 10.69 & & 53.43 & & \\
\hline P-ad6 & 19.00 & 25.31 & 6.31 & & 33.20 & & \\
\hline P-ad8 & 13.00 & 13.43 & 0.43 & & 3.31 & & \\
\hline P-ad12 & 6.00 & 2.65 & 3.35 & & 55.84 & & \\
\hline
\end{tabular}

The $R^{2}$ value generated is $88.73 \%$. The $\mathrm{R}^{2}$ value is above $90 \%$ and this shows that there is a reasonable correlation between the actual char yields and the predicted char yields, although the value of $R^{2}$ is not as good as hoped (at least 95\%).The average error and the average percentage error for this model were found to be 5.77 and $14.58 \%$. A graph of the predicted versus actual data is shown in Figure 2. 


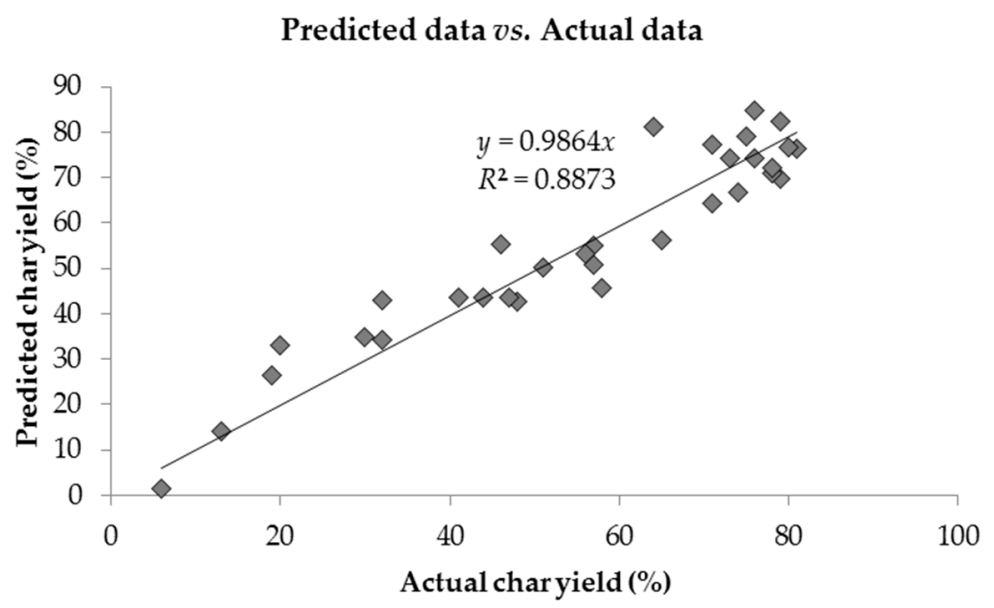

Figure 2. Partial Least Squares (PLS) regression graph of prediction of char yield vs. actual char yield of lowest energy molecular structures.

The leave-one-out-cross-validation (LOOCV) test was used to validate the model generated. 22P-a was chosen as the one to be left out for the test and the structure of 22P-a is shown in Figure 3.

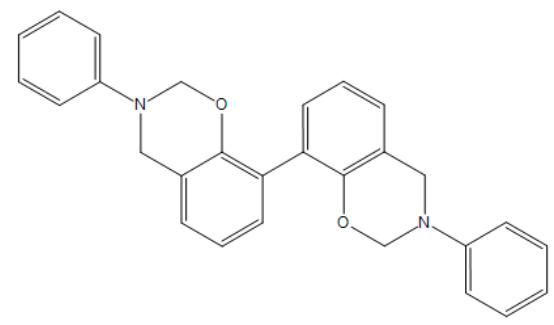

Figure 3. Structure of 22P-a.

The actual percentage yield for this material is $45 \%$ [26] and the prediction data generated by the linear model equation carried out in-silico is $45.13 \%$. The percentage error and the difference error of both readings are less than 1 (Table 7).

Table 7. Validation value and percentage error.

\begin{tabular}{ccccc}
\hline Material & Actual data (\%) & Prediction data (\%) & \% error & Difference error \\
\hline $22 \mathrm{P}-\mathrm{a}$ & 45.00 & 45.31 & 0.69 & 0.31 \\
\hline
\end{tabular}

The small value of percentage error between the readings shows that although the $r^{2}$ is less than $95 \%$ and the average percentage error is $13 \%$, the model can still give a good prediction for the chosen material. This is a very interesting as the validation confirmed that the model is capable of predicting the percentage char yields of benzoxazines with common structures. However, the model is not yet powerful enough to carry out a prediction on a benzoxazine with an unfamiliar functional group.

To investigate the model further, a graph of actual char yield (with 10\% error bar) and predicted char yield was plotted in Figure 4 . A percentage error of $10 \%$ was taken as a reference as generally experimental error will fall within this $10 \%$ error. Figure 4 shows that there are thirteen benzoxazines whose predicted values exceed the $10 \%$ error bars. The list of the molecules and their structures are presented in Table 8. 
Actual char yield (with $10 \%$ error bar) and Predicted char yield

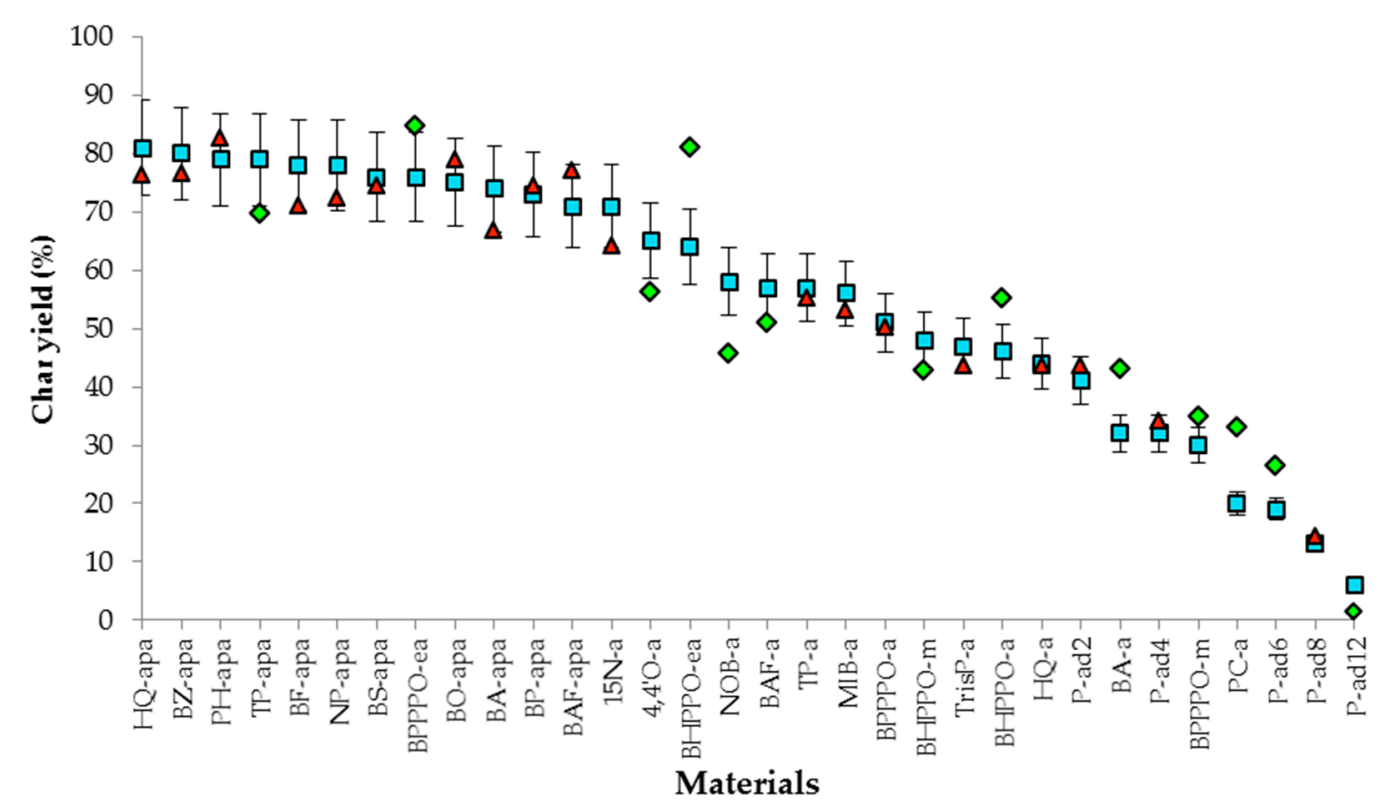

Figure 4. Actual char yield with $10 \%$ error bars and prediction char yield plotted together. (Blue squares: Actual char yield; Red triangles: Predicted char yield (within 10\% percentage error); Green diamonds: Predicted char yield (exceeds 10\% percentage error).

Table 8. List of benzoxazines with percentage error more than $10 \%$.

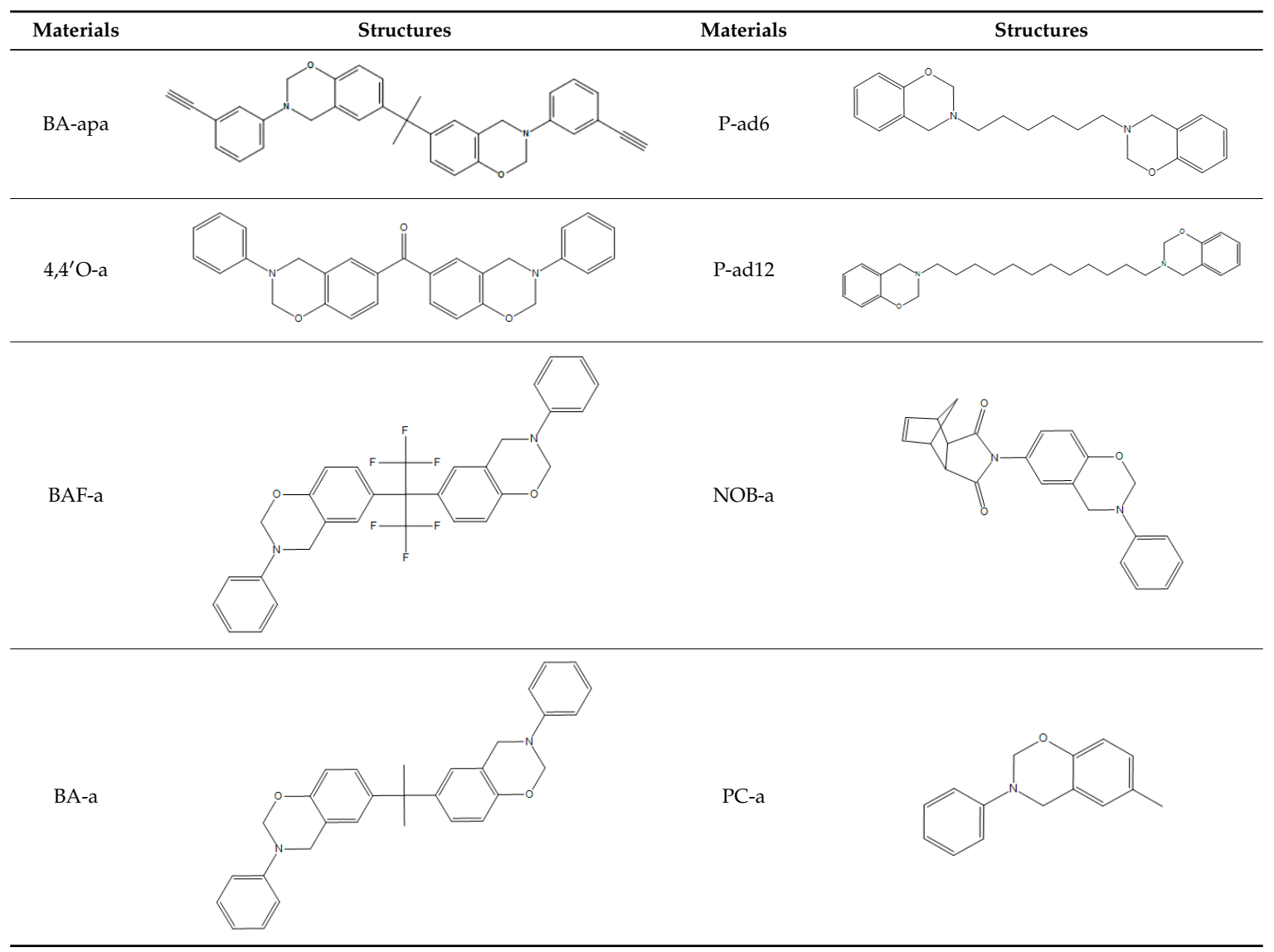


Table 8. Cont.

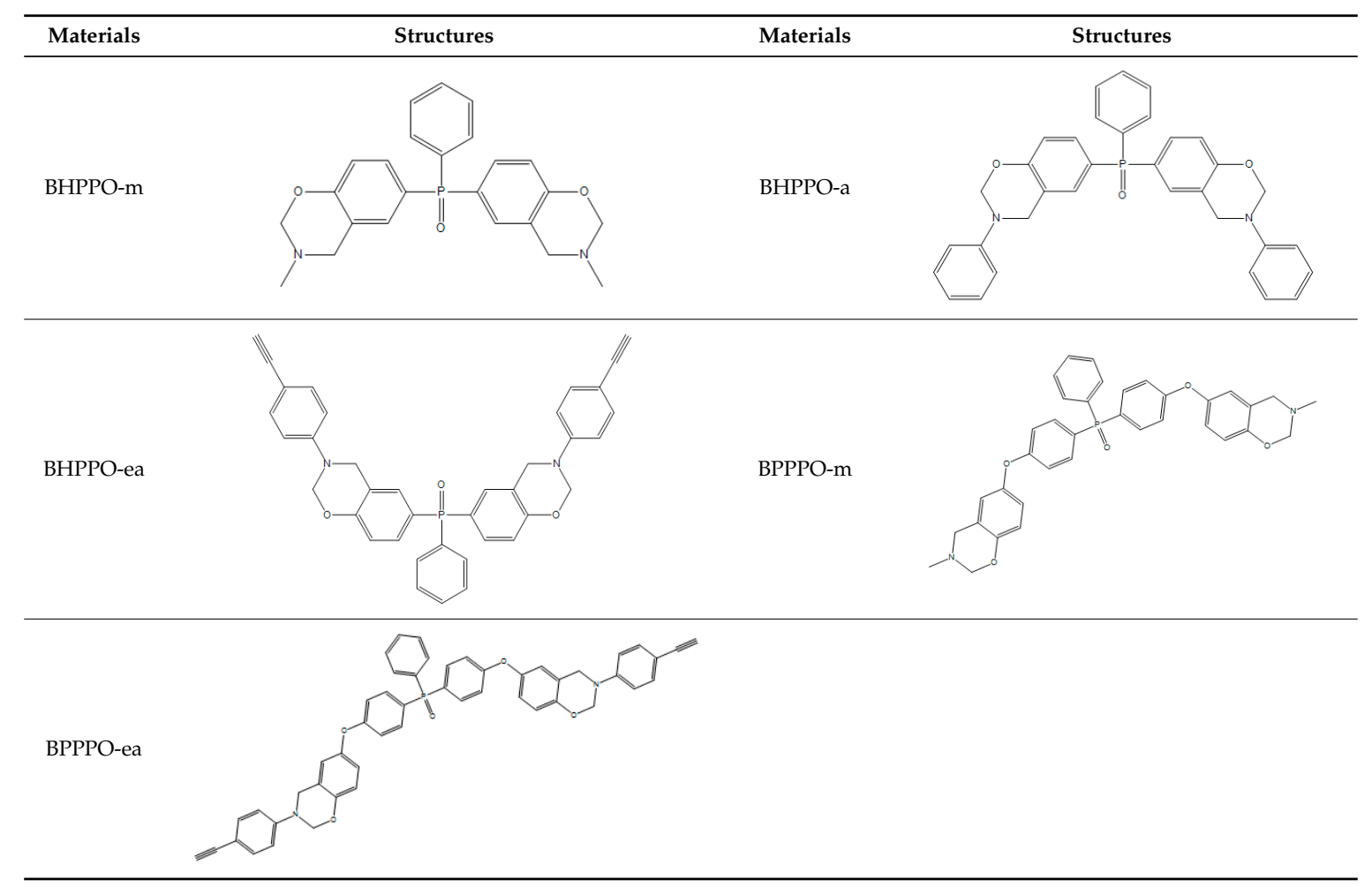

\section{Van Krevelen Calculations}

The Van Krevelen method [35] doesn't have group contributions for groups containing sulphur, oxygen and nitrogen atoms that are similar to the structure of the benzoxazine monomers. It also does not include the contribution of halogen atoms to the calculation and we have two benzoxazines with halogen atoms in our data set. We have tried the Van Krevelen prediction method on our benzoxazine set to see if this method will produce a better prediction. However, the result shows that it does not work well with the benzoxazines in our data set with an $R^{2}$ of only $59.23 \%$ compared to the $R^{2}$ produced by our method which is $88.73 \%$.

\section{Conclusions}

The field of QSPR of benzoxazines is developing rapidly, assisted by the compilation of data in accessible reference sources. As with all data, curation is required, particularly with data that does not have a strictly defined value, e.g., glass transition temperature, which —not being a first order thermodynamic transition - can exhibit a range of values. However, data that has a lower degree of "error" is capable of being predicted to within experimental error or to within $10 \%$ of the value, e.g., char yield, as shown by this work. However, as with all predictions based on molecular structure, the need for accurate models is paramount and as shown here it is wise to take conformational flexibility into account in the models used. In common with all QSPR modelling, when the structure being modelled is 'unusual' in some way, it leads to a larger error in the predictions. However, with the advent of increasing computer power and accuracy in molecular modelling and the rise of faster data processing, the field will see rapid progress in future. The prediction clearly shows that in order to design benzoxazine monomers that will have a higher char yield then increasing the number of rotatable bonds in the monomer and/or increasing the accessible surface area are valid routes.

Supplementary Materials: The following are available online at www.mdpi.com/2073-4360/8/5/166/s1. Table S1: Structures of benzoxazines in the training set.

Acknowledgments: No funds were directly allocated to cover open access publishing costs. 
Author Contributions: Brendan Howlin and Ian Hamerton conceived and designed the experiments; Maryam Sairi performed the experiments; Brendan Howlin and Maryam Sairi analyzed the data; Ian Hamerton contributed analysis tools; Brendan Howlin and Ian Hamerton wrote the paper.

Conflicts of Interest: The authors declare no conflict of interest.

\section{Abbreviations}

The following abbreviations are used in this manuscript:

BAF-a

PH-apa

BF-apa

HQ-apa

BA-apa

BP-apa

TP-apa

BAF-apa

BS-apa

BO-apa

BZ-apa

NP-apa

PC-a

BA-a

HQ-a

$15 \mathrm{~N}-\mathrm{a}$

TP-a

TrisP-a

22P-a

$4,4^{\prime} \mathrm{O}-\mathrm{a}$

P-ad2

P-ad4

P-ad6

P-ad8

P-ad12

MIB-a

NOB-a

BHPPO-a

BHPPO-m

BHPPO-ea

BPPPO-a

BPPPO-m

BPPPO-ea
bisphenolAF/aniline benzoxazine benzoxazine

$N$-aminophenyl-acetylene phenol benzoxazine

$N$-aminophenyl-acetylene bisphenol F benzoxazine

$N$-aminophenyl-acetylene hydroquinone benzoxazine

$N$-aminophenyl-acetylene bisphenol A benzoxazine

$N$-aminophenyl-acetylene $4,4^{\prime}$-dihydroxy biphenyl benzoxazine

$N$-aminophenyl-acetylene $4,4^{\prime}$-thiodiphenol benzoxazine

$N$-aminophenyl-acetylene bisphenol AF benzoxazine

$N$-aminophenyl-acetylene bisphenol S benzoxazine

$N$-aminophenyl-acetylene bisphenol $\mathrm{O}$ benzoxazine

$\mathrm{N}$-aminophenyl-acetylene $4,4^{\prime}$-dihydroxybenzophenone benzoxazine

$N$-aminophenyl-acetylene 2,7-dihydroxynaphtalene benzoxazine

p-cresol/aniline benzoxazine

bisphenol A/aniline benzoxazine

hydroquinone/aniline benzoxazine

1,5-dihydronaphtalene/aniline benzoxazine

4,4'-thiodiphenol/aniline benzoxazine

1,1,1-tris( $p$-hydroxyphenyl)-ethane/aniline benzoxazine

2,2'-dihydroxybiphenyl/aniline benzoxazine

4, $4^{\prime}$-dihydroxybenzophenone/aniline benzoxazine

ethlenediamine bisphenol benzoxazine

$N$-1,4-diaminobutane bisphenol benzoxazine

$N$-1,6-diaminohexane bisphenol benzoxazine

$N$-1,8-diaminooctane bisphenol benzoxazine

$N$-1,12-diaminododecane bisphenol benzoxazine

1-(4-hydro-phenyl)-pyrrole-2,5-dione/aniline benzoxazine

$p$-hydroxyphenylnadimide/aniline benzoxazine

bis-(4-hydroxyphenyl)phenylphospine oxide benzoxazine

methylamine bis-(4-hydroxyphenyl)phenylphospine oxide benzoxazine

3-ethylaniline bis-(4-hydroxyphenyl)phenylphospine oxide benzoxazine

bis-(4-benzyloxyphenoxy-4'-phenyl)phenyl phosphine/aniline benzoxazine

methylamine

bis-(4-benzyloxyphenoxy-4'-phenyl)phenyl

phosphine benzoxazine

3-ethylaniline

bis-(4-benzyloxyphenoxy-4'-phenyl)phenyl

phosphine benzoxazine 


\section{References}

1. Hamerton, I.; Mooring, L. The use of thermosets in aerospace applications. In Thermosets: Structure, Properties and Applications; Guo, Q., Ed.; Woodhead Publishing: Cambridge, UK, 2012; pp. 189-227.

2. Lu, S.-Y.; Hamerton, I. Recent developments in the chemistry of halogen-free flame retardant polymers. Prog. Polym. Sci. 2002, 27, 1661-1712. [CrossRef]

3. Ishida, H. Overview and historical background of polybenzoxazine research. In Handbook of Benzoxazine Resins; Ishida, H., Agag, T., Eds.; Elsevier: Amsterdam, The Netherlands, 2011; pp. 8-66.

4. Alger, M.S. High-temperature and fire resistant polymers. In Specialty Polymers; Dyson, R.W., Ed.; Blackie Academic and Professional: Glasgow, UK, 1998; pp. 189-227.

5. Gardziella, A.; Pilato, L.A.; Knop, A. Phenolic Resins: Chemistry, Applications, Standardisation, Safety and Ecology; Springer: Berlin, Germany, 2000; p. 560.

6. Hamerton, I. Recent Developments in Epoxy Resins; iSmithers Rapra Publishing: Shawbury, UK, 1996.

7. Aerospace Product Selector Guide. Available online: http://www.henkel-adhesives.com/com/content_data/ 372069_ASA15010_Structural_Adhesive_A4_02.pdf (accessed on 20 April 2016).

8. Hamerton, I.; Thompson, S.; Howlin, B.J.; Stone, C.A. New method to predict the thermal degradation behavior of polybenzoxazines from empirical data using structure property relationships. Macromolecules 2013, 46, 7605-7615. [CrossRef]

9. Ginzburg, V.V.; Weinhold, J.D.; Trefonas, P. Computational modeling of block-copolymer directed self-assembly. J. Polym. Sci. Part B 2015, 53, 90-95. [CrossRef]

10. Kandare, E.; Griffin, G.; Feih, S.; Gibson, P.; Lattimer, B.; Mouritz, A. Fire structural modelling of fibre-polymer laminates protected with an intumescent coating. Compos. Part A 2012, 43, 793-802. [CrossRef]

11. Li, C.; Strachan, A. Molecular scale simulations on thermoset polymers: A review. J. Polym. Sci. Part B 2015, 53, 103-122. [CrossRef]

12. Patel, H.C.; Tokarski, J.S.; Hopfinger, A.J. Molecular modeling of polymers 16. gaseous diffusion in polymers: A quantitative structure-property relationship (QSPR) analysis. Pharm. Res. 1997, 14, 1349-1354. [CrossRef] [PubMed]

13. Katritzky, A.R.; Sild, S.; Karelson, M. Correlation and prediction of the refractive indices of polymers by QSPR. J. Chem. Inf. Model. 1998, 38, 1171-1176. [CrossRef]

14. Bicerano, J. Prediction of Polymer Properties, 3rd ed.; Marcel Dekker: New York, NY, USA, 2002; p. 784.

15. Mhlanga, P.; Wan Hassan, W.A.; Hamerton, I.; Howlin, B.J. Using combined computational techniques to predict the glass transition temperatures of aromatic polybenzoxazines. PLoS ONE 2013, 8, e53367. [CrossRef] [PubMed]

16. Labute, P. LowModeMD-Implicit low-mode velocity filtering applied to conformational search of macrocycles and protein loops. J. Chem. Inf. Model. 2010, 50, 792-800. [CrossRef] [PubMed]

17. Labute, P. A widely applicable set of descriptors. J. Mol. Graph. Model. 2000, 18, 464-477. [CrossRef]

18. Wold, S.; Sjöström, M.; Eriksson, L. PLS-regression: A basic tool of chemometrics. Chemom. Intell. Lab. Syst. 2001, 58, 109-130. [CrossRef]

19. Rafaeilzadeh, P.; Tang, L.; Liu, H. Cross-validation. In Encyclopedia of Database Systems; Liu, L., Ozsu, M.T., Eds.; Springer: New York, NY, USA, 2009; pp. 532-538.

20. Kim, H.J.; Brunovska, Z.; Ishida, H. Synthesis and thermal characterization of polybenzoxazines based on acetylene-functional monomers. Polym. J. 1999, 40, 6565-6573. [CrossRef]

21. Low, H.Y.; Ishida, H. Structural effects of phenols on the thermal and thermo-oxidative degradation of polybenzoxazines. Polym. J. 1999, 40, 4365-4376. [CrossRef]

22. Ishida, H.; Ohba, S. Synthesis and characterization of maleimide and norbornene functionalized benzoxazines. Polym. J. 2005, 46, 5588-5595. [CrossRef]

23. Choi, S.W.; Ohba, S.; Brunovska, Z.; Hemvichian, K.; Ishida, H. Synthesis, characterization and thermal degradation of functional benzoxazine monomers and polymers containing phenylphosphine oxide. Polym. Degrad. Stab. 2006, 91, 1166-1178. [CrossRef]

24. Allen, D.J.; Ishida, H. Physical and mechanical properties of flexible polybenzoxazine resins: Effect of aliphatic diamine chain length. J. Appl. Polym. Sci. 2006, 101, 2798-2809. [CrossRef]

25. Agag, T.; Takeichi, T. Synthesis and characterization of novel benzoxazine monomers containing allyl groups and their high performance thermosets. Macromolecules 2003, 36, 6010-6017. [CrossRef] 
26. Shen, S.B.; Ishida, H. Dynamic mechanical and thermal characterization of high-performance polybenzoxazines. J. Polym. Sci. Part B 1999, 37, 3257-3268. [CrossRef]

27. Principles of Thermal Analysis and Calorimetry; Haines, P.J., Ed.; Royal Society of Chemistry (RSC): Cambridge, UK, 2002; pp. 69-72.

28. Jain, R.; Narula, A.K.; Choudhary, V. Studies on curing and thermal behavior of diglycidyl ether of bisphenol-A and benzoxazine mixtures. J. Appl. Polym. Sci. 2007, 106, 3327-3334. [CrossRef]

29. Santhosh Kumar, K.S.; Reghunadhan Nair, C.P.; Sadhana, R.; Ninan, K.N. Benzoxazine-bismaleimide blends: Curing and thermal properties. Eur. Polym. J. 2007, 43, 5084-5096. [CrossRef]

30. Nour-Eddine, E.M.; Yuan, Q.; Huang, F. Investigation of curing and thermal behavior of benzoxazine and lignin mixtures. J. Appl. Polym. Sci. 2012, 125, 1773-1781. [CrossRef]

31. Lorjai, P.; Wongkasemjit, S.; Chaisuwan, T.; Jamieson, A.M. Significant enhancement of thermal stability in the non-oxidative thermal degradation of bisphenol-A/aniline based polybenzoxazine aerogel. Polym. Degrad. Stab. 2011, 96, 708-718. [CrossRef]

32. Thompson, S. Examining the Thermal Degradation of Polybenzoxazines and Their Resultant Chars. Ph.D. Thesis, University of Surrey, Guildford, UK, 2013; pp. 105-112.

33. McNamara, L.T. Characterisation of A Selection of Commercial Benzoxazines and Novel Toughtening Strategies. Ph.D. Thesis, University of Surrey, Guildford, UK, 2013; pp. 102-105.

34. Wan Hassan Wan, H. Characterisation and Molecular Modelling of Selected Benzoxazines and Their Polymers. Ph.D. Thesis, University of Surrey, Guildford, UK, 2014; p. 206.

35. Van Krevelen, D.W.; Te Nijenhuis, K. Properties of Polymers, Their Correlation with Chemical Structure; Their Numerical Estimation and Prediction from Additive Group Contributions, 4th ed.; Elsevier: Amsterdam, The Netherlands, 2009.

(C) 2016 by the authors; licensee MDPI, Basel, Switzerland. This article is an open access article distributed under the terms and conditions of the Creative Commons Attribution (CC-BY) license (http://creativecommons.org/licenses/by/4.0/). 